\section{FACULTY POSITION IN CIVIL AND}

\section{ENVIRONMENTAL ENGINEERING AT MSU}

The Department of Civil \& Environmental Engineering (CEE) at Michigan State University (MSU) invites applications for a tenure-track faculty position in the area of materials with a focus on the synthesis and characterization of advanced and complex materials. Competitive applicants will have a demonstrated record of excellence in the development, synthesis and experimental characterization of advanced structural materials, multifunctional materials and complex materials.

The position is open to all levels. Applicants must hold an earned doctorate in a field related to the position focus, and demonstrate exceptional promise for high-quality research, teaching, and professional development. A tenured appointment will be considered for candidates with a recognized record of exceptional achievement. Given the crossdisciplinary nature of the research expertise sought, applicants should realize that the appointment (tenure home) will be in the Department of Civil and Environmental Engineering. As such, the successful candidate will be expected to develop a strong and independent externally-funded research program that enhances the existing research activities in the areas of structural engineering, materials and mechanics in the CEE department. The appointee will be responsible for teaching undergraduate and graduate courses as part of the CEE department curricula.

Interested individuals should submit an application for this position through: http://jobs.msu.edu/ and refer to position \#6979. Applicants must submit a detailed resume, a teaching and research plan (3 pages maximum), and the names and contact information for three references. The application material should be accompanied by a cover letter stating the position specialty being applied to and a brief statement of their interest in the position. Applications will be reviewed on a continuing basis until the position is filled. For full consideration, applications should be received before December 31, 2013. Nominations or questions are welcome by contacting the search committee chair through email at CEE-SEMM-Search@egr.msu.edu

\section{MICHIGAN STATE

U N I V E R S I T Y

MSU is committed to achieving excellence through cultural diversity. The University actively encourages applications and/or nominations of women, persons of color, veterans and persons with disabilities.

\section{MSU is an Affirmative Action, Equal Opportunity Employer.}

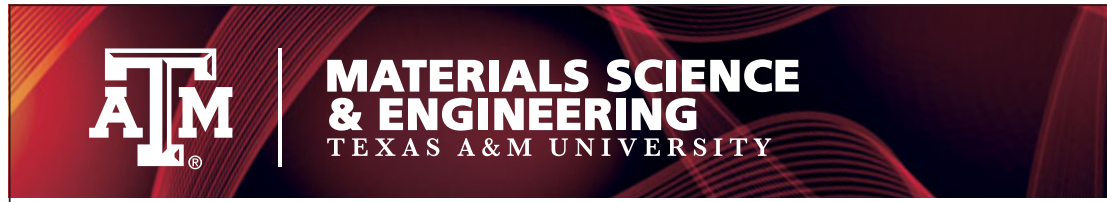

\section{MULTIPLE FACULTY POSITIONS, ALL RANKS \\ Materials Science and Engineering}

The interdisciplinary Department of Materials Science and Engineering at Texas A\&M University invites applications for multiple tenured or tenure-track faculty positions. Although we primarily seek candidates at the associate- and full-professor levels, exceptional candidates at the assistant-professor level will be also considered.

Applicants must have an earned doctorate in materials science and engineering or an appropriate, closely related discipline. Specifically targeted are candidates with expertise in one or more of the following areas: (a) Computational materials science; (b) Advanced polymer design, synthesis, and processing science; (c) Materials electrochemistry; and (d) Materials degradation and corrosion. Highly qualified candidates in other areas of materials science and engineering will also be considered.

The successful applicants will teach at the undergraduate and graduate levels; develop an independent, externally funded research program; participate in all aspects of the department's activities; and serve the profession. Strong written and verbal communication skills are required. Full position ad can be found at msen.tamu.edu with further details.

Applicants should submit a cover letter stating the position they are interested in, curriculum vitae, teaching and research statements, and a list of four references (including postal addresses, phone numbers and email addresses) to the website: www.tamuengineeringjobs. com/applicants/Central? quickFind=54918

Full consideration will be given to applications received by January 3, 2014. Applications received after that date may be considered until positions are filled. It is anticipated that appointments will begin Fall 2014.

Texas A\&M University is an Equal Opportunity Employer
TENURE-TRACK FACULTY POSITIONS

College of Engineering and Applied Sciences

\section{Nanjing University}

The College of Engineering and Applied Sciences invites applications for tenuretrack faculty positions at the associate or full professor level for the Department of Materials Sciences and Engineering. Specific areas of interest include:

1. Informational materials: optoelectronic and non-linear optical materials, semiconductor materials, etc.;

2. Energy materials: energy-storing materials, photovoltaic cells, etc.;

3. Biomaterials and medical materials;

4. Material engineering: crystal growing, interface structure and properties, thin and ultrathin film fabrication technology (MBE/ MOCVD/sputtering), etc.

5. Computational materials science, Materials Genome Project.

Outstanding candidates with a PhD degree in any area related to materials science and engineering, quantum electronics and optical engineering, biomedical engineering, and energy science and engineering will be considered. Postdoctoral research experience is preferred.

We provide: start-up fund of 2 to 5 million RMB; annual salary of 160 to $400 \mathrm{~K}$ RMB; lab space: 100 to $150 \mathrm{~m}^{2}$; house: 120 to $140 \mathrm{~m}^{2}$

Please submit application materials, including: a) curriculum vitae, b) names and contact information of three references, c) three representative papers, d) research plan, and e) teaching plan, to Prof. Yi-qiang Qin via e-mail at job_eng@nju.edu.cn; College of Engineering and Applied Sciences, Nanjing University, Nanjing, China 210093; Phone: +86-2583686587

For more information, please visit http:// eng.nju.edu.cn/index.php/en/jobs.

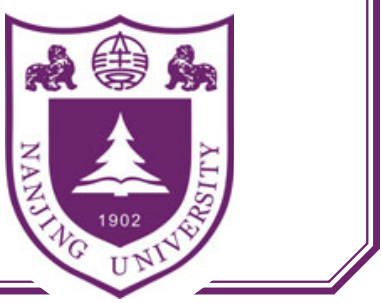




\title{
FACULTY SEARCH
}

\author{
Materials Science and Engineering \\ Virginia Polytechnic Institute and State University
}

The Department of Materials Science and Engineering (MSE) at Virginia Tech seeks applications to fill a tenure-track faculty position at the Assistant/Associate Professor level. A doctoral degree or equivalent in a relevant area of materials science and engineering is required. Exceptional candidates at the senior level may be considered.

The successful candidate will be expected to conduct scholarly research in an area that can contribute to experimental macromolecular science and engineering (as evidenced by a strong record of peer-reviewed scholarly publications) and to teach at the undergraduate and graduate levels. Candidates with research interests in all areas of polymer engineering/polymer science will be considered. Candidates with backgrounds and accomplishments in fundamental and applied properties of polymeric membrane materials, polymeric based composites and nanocomposites, or advanced polymer characterization science are especially encouraged to apply. The successful candidate will also be expected to form collaborative ties between MSE and the Macromolecules and Interfaces Institute (www.mii.vt.edu).

Virginia Tech is located 45 miles west of Roanoke in the scenic foothills of the Blue Ridge Mountains. A growing corporate research center is located adjacent to the campus. Additional information is available online for the MSE Department (www.mse.vt.edu), the College of Engineering (www.eng.vt.edu), the centralized characterization facilities (www.ncfl.ictas.vt.edu), the Institute for Critical Technology and Applied Science (www.ictas.vt.edu), and the town of Blacksburg (www.blacksburg.gov).

Applicants should apply at www.jobs.vt.edu to posting number TR0130145, and include a resume, a statement of research and teaching interests, and the names of three references. Initial review of applications will begin on January 6, 2014, and will continue until the position is filled.

Virginia Tech does not discriminate against employees, students, or applicants on the basis of age, color, disability, gender, national origin, political affiliation, race, religion, sexual orientation, or veteran status. Anyone having questions concerning discrimination should contact the Office for Equal Opportunity. Individuals with disabilities desiring accommodations in the application process should notify Amy Hill, amy@mse.vt.edu, 540-231-9125.

Virginia Tech is the recipient of the National Science Foundation ADVANCE Institutional Transformation Award to increase the participation of women in academic science and engineering careers (www.advance.vt.edu).

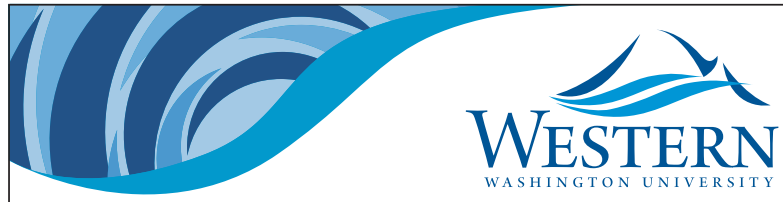

\section{FACULTY POSITION}

Advanced Materials Science and Engineering Center Western Washington University

The Advanced Materials Science and Engineering Center (AMSEC) of Western Washington University invites applications for a tenuretrack faculty position at the assistant professor level in the field of computational materials science, with a focus on energy materials (broadly defined). A PhD degree in Chemistry, Physics, Materials Science, or a related field and postdoctoral (or equivalent) experience are required. This interdisciplinary position will include an appointment in Chemistry or Physics and will have an ongoing affiliation with AMSEC and the Institute for Energy Studies (IES).

The successful candidate is expected to establish a vigorous, externally-funded research program involving students and to teach courses in their home department and AMSEC. Applicants should submit their application online at www.wwu.edu/jobs. Applications should include a cover letter; full CV; undergraduate and graduate transcripts; a statement of research plans (5 pages max.); and a statement of teaching philosophy and interests (1 page max.). In addition, applicants should arrange to have three letters of recommendation e-mailed to AMSEC.FacultySearch@wwu.edu. Review of applications will begin on January 13,2014 , and continue until the position is filled. For disability accommodation call (360) 650-3774 (V) or (360) 650-7967 (TTY).

$A A / E O E$
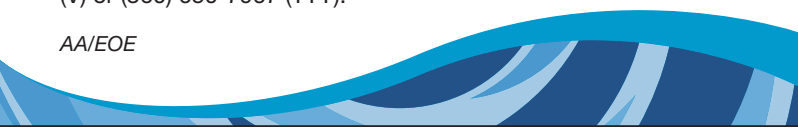

Soft Materials (Organic Molecular or Polymer)
Synthesis or Simulation
Department of Materials Science and Engineering/
Department of Chemical and Biomolecular Engineering
The University of Delaware College of Engineering invites applications for a tenure-track facul-
ty position with a focus on organic molecular or polymer synthesis or on the simulation/theoret-
ical analysis of soft materials. The University has a growing nucleus of researchers engaged
in soft materials research, and the ideal applicants will establish a research program primarily
focused on soft materials with the ability to engage in sustained interactions across the College
and University. Candidates seeking an interdisciplinary appointment between Departments in
the College of Engineering are especially encouraged to apply. It is expected that the success-
ful candidate will demonstrate a strong commitment to excellence in research and teaching, be
qualified to teach core courses at all levels within the respective curriculum, and establish an
externally funded and highly visible research program that complements current soft materials
research activities at the University. We are seeking individuals who dare to be first and will be
the thought leaders of their disciplines.
Candidates must have a PhD degree in engineering or a related discipline and will join an engi-
neering department appropriate to their area of expertise. Applicants should submit a curricu-
lum vitae, a one-page statement of teaching experience and interests, a 3-6-page research pro-
posal, and three references. The University of Delaware values diversity and is supportive of
the needs of dual-career couples; women and minorities are especially encouraged to apply.
For additional information about the position and to submit applications please visit the
UDJOBS website at www.udel.edu/udjobs. Application review will begin by 15 December 2013,
although nominations and applications will be accepted until the position is filled. All applica-
tion materials will be shared with department faculty.
The UNIVERSITY OF DELAWARE is an Equal Opportunity Employer,
and encourages applications from Minority Group Members and Women.




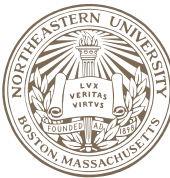 Northeastern \\ Asst/Assoc/Full Professor Computational Science and Engineering}

Requisition Number: FTFR000409

Division/College: College of Engineering

FT/PT: Full Time

\section{Position Summary:}

As part of a significant college-wide expansion crossing disciplinary boundaries, the Mechanical and Industria Engineering Department at Northeastern University in Boston, MA invites applications and nominations for four tenured and tenure-track Associate or Full Professors to establish internationally recognized research programs for September 2014. Applicants with exceptional qualifications will also be considered for tenuretrack positions at the Assistant Professor level. This cluster hire is focused on Computational Science and Engineering in the emerging areas of applied mechanics, thermo-fluid sciences and materials science to complement the existing research streams of the department and of Northeastern University's strategic research areas of Sustainability, Security, and Healthcare.

Guided by Northeastern University's strategic growth plans in the above mentioned areas, existing faculty and the new faculty hires in Mechanical and Industrial Engineering have unique opportunities to collaborate with faculty across campus, to significantly impact the direction and trajectory of this already strong, vibrant department. Demonstrated excellence in research, teaching, and collaborative background that spans traditional as well as our primary thrust areas is highly desirable.

\section{Qualifications:}

Applicants must have a doctorate degree in engineering or a related field of study in one of the areas of interest listed above by the start date, and those applying at the Associate Professor or Professor levels must have a wellestablished academic record, including scholarly publications and an externally funded research program.

\section{Additional Information:}

The Mechanical and Industrial Engineering Department (www.mie.neu.edu) at Northeastern University, ranked among top 50 in the nation by US News and World Report, is a successful and vibrant academic enterprise which is growing in both size and stature. The department comprises 44 full-time faculty with $\$ 10$ million in annual research funding, $110 \mathrm{PhD}, 420 \mathrm{MS}$, and 1,200 undergraduate students. At the core of the Northeastern engineering education experience is our top-ranked cooperative education program, which contributes significantly to the integrated learning model of the College of Engineering. In addition, of the eight federally-funded research centers in the College of Engineering, four are based in the MIE Department: 1) The NSF Nanoscale Science and Engineering Center (NSEC) for High-rate Nanomanufacturing, 2) The NSF Center for Health Organization Transformation, 3) The NSF Center for Microcontamination Control, and 4) The VA New England Healthcare Engineering Partnership. Northeastern University is also an inaugural member of the Massachusetts Green High Performance Computing Center that is being developed as a world-class, highperformance academic research computing facility in Holyoke MA.

Applicants should submit a detailed Curriculum Vita, a clear statement of specific teaching and research interests and objectives, along with names, e-mail addresses and phone numbers of at least three professional references. To apply please visit http://apptrkr.com/406124. The positions will remain open until filled.

\section{Equal Opportunity Employer}

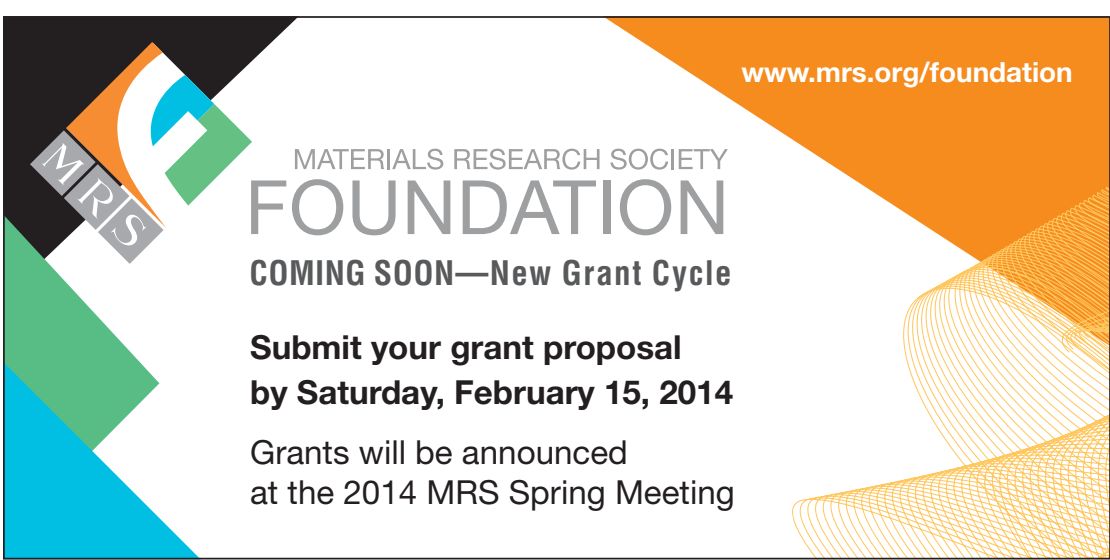

\section{FACULTY POSITIONS}

Materials Engineering Department

California Polytechnic State University

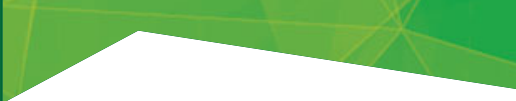

The Materials Engineering Department at California Polytechnic State University, San Luis Obispo (www. mate.calpoly. edu), invites applications for two fulltime tenure-track faculty positions starting Fall 2014 in the areas of:

- Sustainable Materials (Reference Job Requisition 103061)

- Microsystem Technologies and Fabrication (Reference Job Requisition 103050)

For full consideration, please apply by the review beginning date of January 15, 2014.

Our vision is to collaboratively overcome the intertwined grand challenges of sustainability and transformative learning through our materials engineering program. Our daily mission is to be a vibrant, creative and effectual learning community that cultivates the unique capabilities of each individual to thrive in a complex, interconnected, and everchanging world. Faculty teach several different materials engineering courses (freshmen to masters level), in addition to conducting scholarship that enriches the student experience. Our projects-based curriculum emphasizes hands-on, learn by doing and guided inquiry.

These positions require experience and commitment to student-centered learning and teaching, as well as the ability to work collaboratively with other disciplinary programs. The Microsystems Technology position will foster collaborations to enable cross-listed courses and research projects with Electrical Engineering, Biomedical Engineering, and other programs. Preference will also be given to those with relevant work experience and those with experience in working with diverse populations.

For detailed position descriptions and application instructions, please visit www.calpolyjobs.org. Questions can be directed to mate@calpoly.edu.

Cal Poly's commitment to diversity informs our efforts in recruitment, hiring, and retention. California Polytechnic State University is an affirmative action/equal opportunity employer.

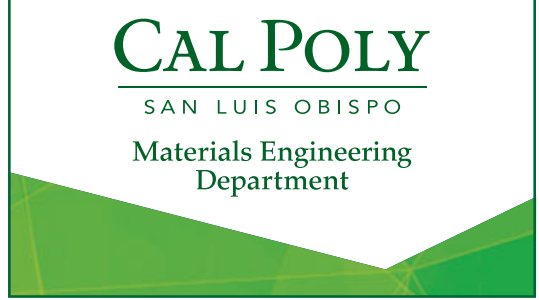




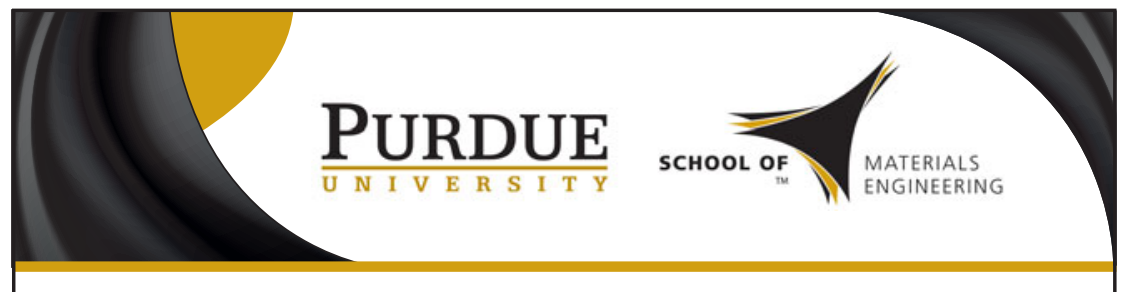

\section{FACULTY POSITION | School of Materials Engineering}

The School of Materials Engineering at Purdue University invites applications for a tenure-track position of Assistant Professor. Purdue University seeks to attract exceptional candidates with interests and expertise in any Materials Science and Engineering area. Successful candidates must hold a PhD degree in Materials Science and Engineering or a related discipline and demonstrate excellent potential to build an independent research program at the forefront of their field, as well as potential to educate and mentor students. Duties include conducting original research, advising graduate students, teaching undergraduate and graduate level courses, as well as performing service both at the School and University levels.

The School of Materials Engineering at Purdue University has experienced significant growth in the past decade and has a strong faculty core engaged in all areas of Materials Science and Engineering, as well as significant interdisciplinary efforts across campus, with other academic institutions, and industrial partners. The College of Engineering at Purdue is currently undergoing extensive growth, with over one hundred faculty position openings being projected over the next five years. For a detailed description of research activities see www.engineering. purdue.edu/MSE/.

Submit applications online at https://engineering.purdue.edu/Engr/AboutUS/Employment/Applications, including curriculum vitae, teaching and research plans (each 3 pages maximum), copies of up to three most relevant publications, and names of three references. For information/questions regarding applications submission, contact Marion Ragland, Faculty Recruitment Coordinator, College of Engineering, Attn: School of Materials Engineering, at ragland@purdue.edu. Address questions regarding the position to Prof. Lia Stanciu, Search Chair at Istan-ciu@purdue.edu. Review of applications begins October 1, 2013 and continues until position is filled. A background check will be required for employment in this position.

Purdue University is an equal opportunity/equal access/affirmative action employer fully committed to achieving a diverse workforce.

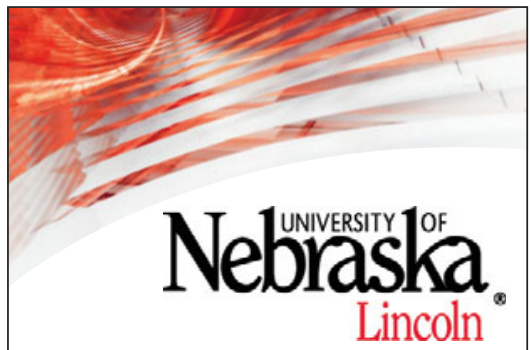

\section{FACULTY POSITIONS Department of Mechanical \& Materials Engineering}

The Department of Mechanical \& Materials Engineering (MME) at the University of Nebraska-Lincoln (http:// mme.unl.edu) invites applications for two tenure-track faculty positions at the Assistant Professor level. Applicants are expected to have a $\mathrm{PhD}$ degree or equivalent in materials science and engineering, mechanical engineering, or a closely related field. Must have a strong record of scholarly achievements in MME priority areas in energy, nanotechnology, biomedical engineering, or materials. The ideal candidates would work on advanced materials/mechanical characterization, nanoengineering, computationally-driven materials/device designs, and failure mechanics. They are also expected to contribute to the undergraduate and graduate academic programs within the department and demonstrate a commitment to excellence in both teaching and research. Opportunities for collaborations across the University of Nebraska include the University of Nebraska Medical Center, the Nebraska Center for Energy Sciences Research, the Nebraska Center for Materials and Nanoscience, and other state- and federally-funded research core facilities and programs.

Applications must be submitted via http://employment.unl.edu, requisition F_130213. A complete application includes a cover letter (with specialty clearly stated), CV, research and teaching statements (4 pages total), and a list of three references. The review of applicants will begin January 15, 2014, and will continue until the positions are filled.

The University of Nebraska has an active National Science Foundation ADVANCE gender equity program, and is committed to a pluralistic campus community through affirmative action, equal opportunity, work-life balance, and dual careers.

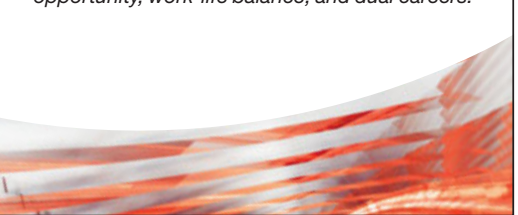




\section{Asst/Assoc/Full Professor - Nanotechnology and Materials}

Requisition Number: FTFR000412 \& FTFR000413

Division/College: College of Engineering

FT/PT: Full Time

\section{Position Summary:}

Northeastern University seeks outstanding faculty candidates for appointments at the associate or full professor level in disciplines related to Nanotechnology and Materials, with specific focus on the emerging areas of biomaterials, computational materials, materiomics for energy, and nanomanufacturing. Successful applicants will lead internationally-recognized research programs that complement existing expertise and align with one or more of Northeastern's strategic research themes of health, security and sustainability. Exceptional candidates at the assistant professor level will also be considered.

- Biomaterials: biomechanics; composites; polymer science; tissue engineering; cellular processes; immune and inflammatory response; ethical issues

- Computational materials: atom-scale simulation and interaction; quantum mechanics and dynamics; multiscale methods; applied physics

- Materiomics for energy: magnetics; chemical physics; metamaterials

- Nanomanufacturing: nanofabrication; nanopatterning; microstructures

\section{Qualifications:}

Doctorate degree in a discipline related to Nanotechnology and Materials or in one of the above listed focus areas by the start date, and a record of publication and research funding commensurate with rank and appointment with tenure required.

\section{Additional Information:}

Note: Requisition Numbers FTFR000412 and FTFR000413 are a part of the same search and applications from both requisitions will be considered altogether.

About Northeastern: Founded in 1898, Northeastern is a global, experiential, research university built on a tradition of engagement with the world, creating a distinctive approach to education and research. Over the past seven years, the university has appointed 387 tenured and tenuretrack faculty members from around the world. Their expertise in established and emerging fields strategically aligns with Northeastern's interdisciplinary research enterprise, which focuses on discovering solutions to global challenges in health, security, and sustainability.

\section{How to Apply:}

Visit the College website at http://apptrkr.com/406164. Application should include (1) detailed resume, (2) research development statement, (3) teaching statement, (4) copy of one sample journal paper, and (5) list of four references with contact information. Screening of applications begins November 15, 2013 and continues until the position is filled. Questions regarding this position should be directed to Prof. Hanchen Huang at h.huang@neu.edu.

\section{Equal Opportunity Employer}

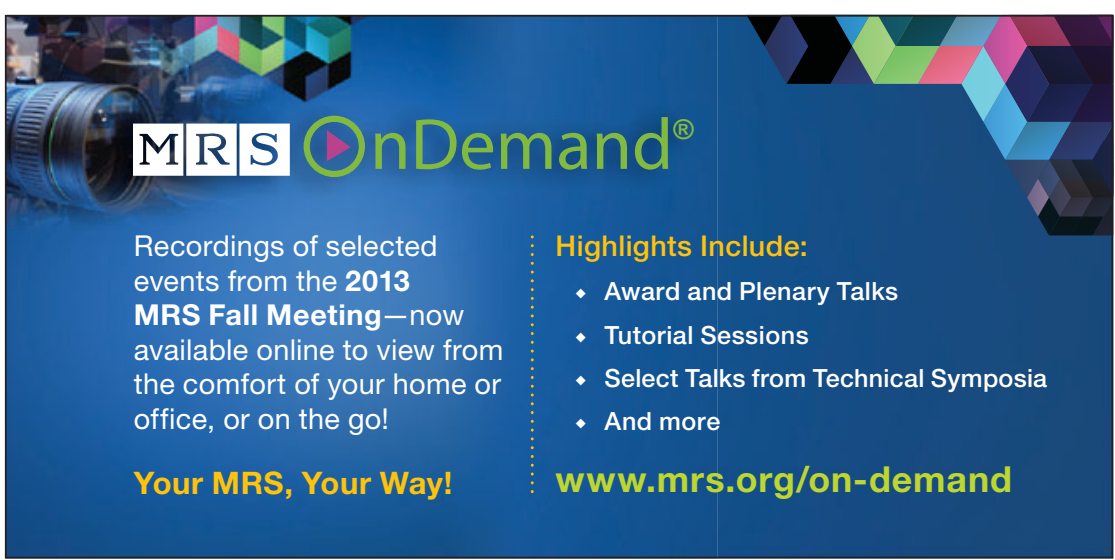

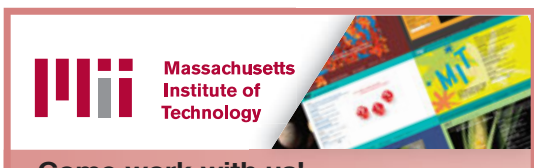

Come work with us!

\section{Faculty Position \\ Department of Materials Science and Engineering}

The Department of Materials Science and Engineering (DMSE) seeks candidates for two open tenure-track faculty positions to begin July 2014 or thereafter.

Appointments would be at the assistant or untenured associate professor level. In special cases, a senior faculty appointment may be possible. Faculty duties include teaching at the graduate and undergraduate levels, research, and supervision of student research.

Candidates should hold a Ph.D. in

Materials Science and Engineering or a related field by the start of employment. Candidates with deep knowledge of the core of Materials Science and Engineering are desired. DMSE seeks to broaden its research portfolio in two areas:

- Electronic and photonic materials. Some topics of interest include: multifunctional materials with cross-properties; photonic materials and photonic/electronic integration; hybrid electronic systems; materials theory for electronic and photonic materials.

- Materials chemistry and structure. Some topics of interest include: multiscale characterization science; low-dimensional materials; surface science; materials chemistry; materials theory.

However, DMSE has strengths and interests across the full spectrum of materials research, and excellent candidates with expertise in any and all areas of the field are welcomed. MIT has a number of Institute-wide initiatives under way or in development, on topics that include Manufacturing, Energy, Environment, and Health. Individuals who can connect to these initiatives are of interest.

Interested candidates should submit application materials electronically at http://dmsefacsrch.mit.edu. Each application should include: a curriculum vitae; a statement of research interests; and a statement of teaching interests. We request that each candidate arrange for 3 letters of reference to be uploaded at http://dmsefacsrch.mit.edu/letters/. Questions should be addressed to DMSE-Search-Master@dmsefacsrch.mit.edu. Responses received by December 31, 2013, will be given priority. No application received after March 1 will be considered in this year's search.

We especially encourage minorities and women to apply because of MIT's strong commitment to diversity in engineering education, research and practice.

MIT is an Equal Opportunity/ Affirmative Action employer. 


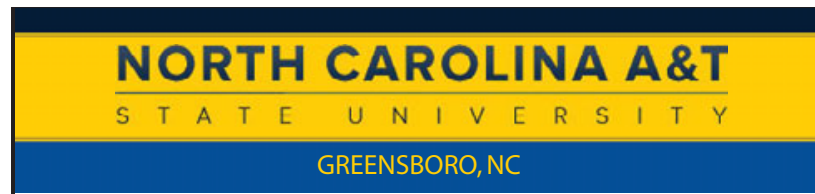

\section{Assistant Professor, Nanoengineering}

The Joint School of Nanoscience and Nanoengineering (JSNN) invites applications for a faculty in the area of research expertise in the fields of nanoengineering and energy systems focusing on novel nanoscale materials, chemistry, or devices for applications in energy, efficiency, and sustainability. JSNN was established as a collaborative education and research program of North Carolina A\&T State University and the University of North Carolina at Greensboro.

Minimum Requirements: Candidate with an earned doctoral degree in an engineering discipline with experience at the intersection of nanotechnology and energy. Two years of postdoctoral experience preferred.

\section{To apply go to: https://jobs.ncat.edu/postings/5291}

North Carolina A\&T State University is a land grant doctoral/ research intensive institution and $\mathrm{AA} / \mathrm{EEO}$ employer.

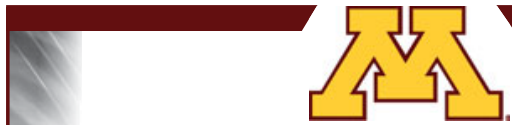

\section{FACULTY POSITION}

\section{Department of Chemical Engineering and Materials Science \\ University of Minnesota}

The Department of Chemical Engineering and Materials Science at the University of Minnesota (www.cems.umn.edu) seeks to fill a faculty position at the Assistant (tenure-track), Associate, or Full Professor level, commensurate with experience. Outstanding candidates with a PhD degree in any area related to chemical engineering and materials science will be considered. Candidates should have a distinguished academic and research record and a commitment to teaching in a highly interdisciplinary department.

Applications, consisting of a CV (including a list of publications), a research plan, a teaching plan, and a list of three references with contact information (including email addresses), should be submitted on-line at https://employment.umn.edu. Search for requisition number 186204. Review of the applications will begin immediately and continue until the position is filled. The successful candidate will be in place as early as Fall 2014.

\section{The University of Minnesota is an equal opportunity educator and employer.}

\section{FACULTY POSITIONS}

International Research Institute for Multidisciplinary Science Beihang University
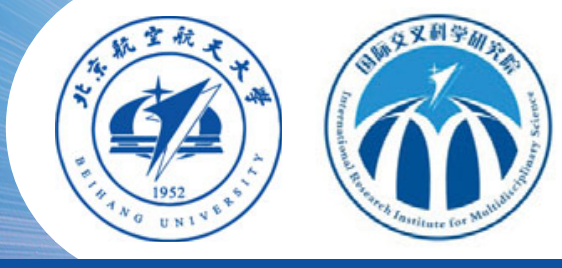

Faculty positions are available at the International Research Institute for Multidisciplinary Science (IRIMS) at Beihang University in Beijing, specifically in the new International Research Center (IRC) for Biological \& Nature-Inspired Materials, led by Professor Robert O. Ritchie. As the core part of IRIMS, this IRC is devoted to establishing a world-class, advanced and multidisciplinary research platform focused on fundamental cutting-edge research in most advanced materials including biological and nature-inspired materials and biomaterials science and engineering. The Center invites applications for full-time Professors, Associate, and Assistant Professors, and postdoctoral scientists, with preference given to younger candidates; e.g., recent PhD graduates and postdoctoral researchers, whose research emphasis demonstrates the potential to complement and advance the IRCs existing research strengths. Successful candidates will be provided competitive salaries and start-up funds, in line with national Youth Thousand Talent Program and Beihang "Zhuoyue" Program.

\section{REQUIREMENTS \& QUALIFICATIONS}

Youth Thousand Talent Professor: Candidates should be under the age of 40; have obtained a PhD degree in a world-renowned university with at least three years of research experience abroad; or have obtained a PhD degree in Mainland China with at least five years of research and teaching experience abroad. Special offers will be granted to those who have excellent research achievements during their doctoral study.

"Zhuoyue" Program Professor and Associate Professor: Candidates should have a PhD degree in a world-renowned university; or have obtained a PhD degree in Mainland China with at least two years (Professor) or one year (Associate Professor) of research experience abroad; and have a proven track record of faculty or research fellow positions abroad before coming to China.

We also welcome eminent scholars all over the world to join the newly-established IRC to create its international excellence.

\section{HOW TO APPLY}

Applicants should send curriculum vitae by email to rscrcb@buaa.edu.cn, with "IRC-Biomaterials Application" in the title. For more information, please visit the University's Human Resource Department website at http://rsc.buaa.edu.cn/; contact us by email at rscrcb@ buaa.edu.cn; or by telephone at 86-010-82317779. 

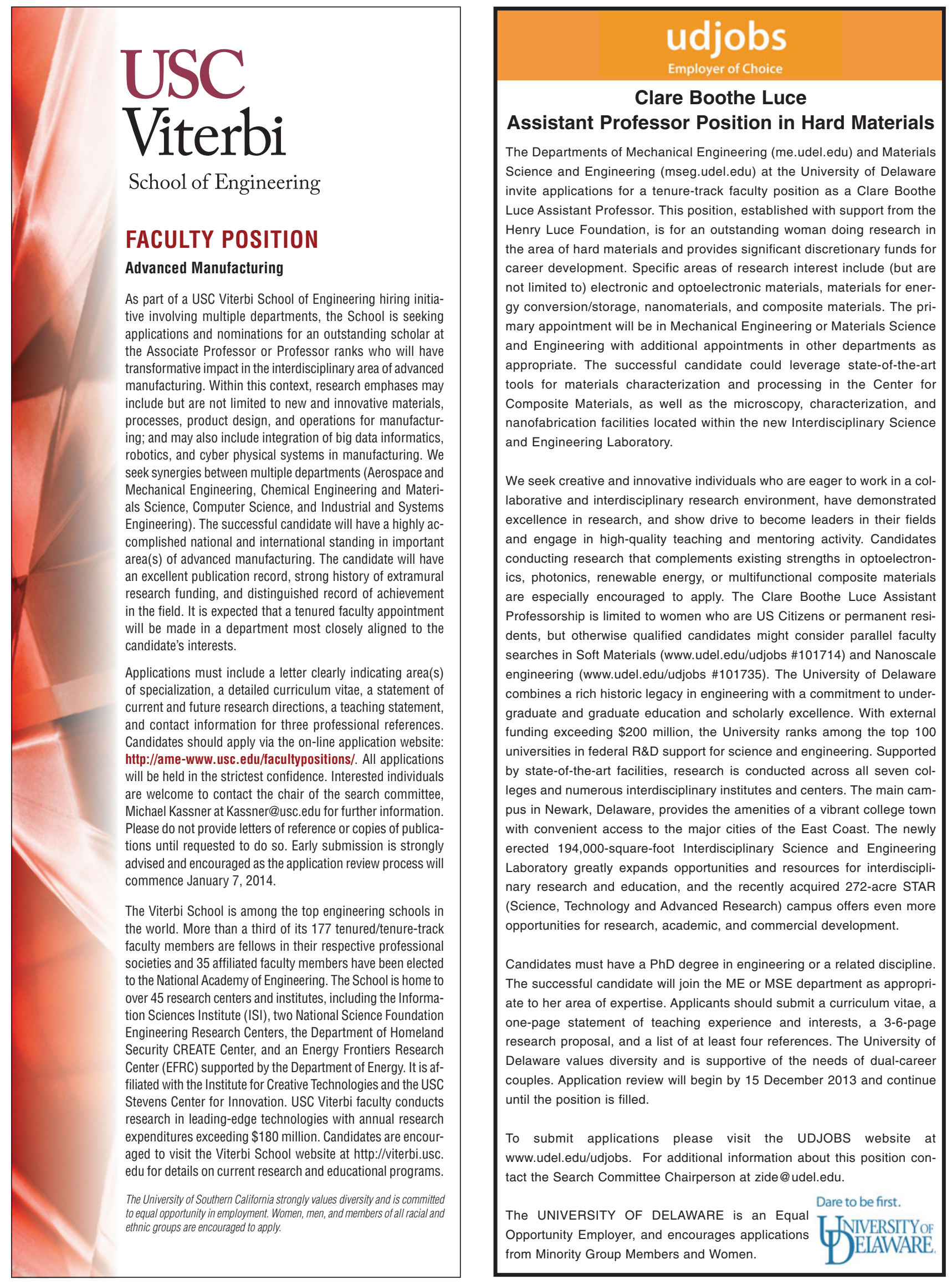

The Departments of Mechanical Engineering (me.udel.edu) and Materials Science and Engineering (mseg.udel.edu) at the University of Delaware invite applications for a tenure-track faculty position as a Clare Boothe Luce Assistant Professor. This position, established with support from the Henry Luce Foundation, is for an outstanding woman doing research in the area of hard materials and provides significant discretionary funds for career development. Specific areas of research interest include (but are not limited to) electronic and optoelectronic materials, materials for energy conversion/storage, nanomaterials, and composite materials. The primary appointment will be in Mechanical Engineering or Materials Science and Engineering with additional appointments in other departments as appropriate. The successful candidate could leverage state-of-the-art tools for materials characterization and processing in the Center for Composite Materials, as well as the microscopy, characterization, and nanofabrication facilities located within the new Interdisciplinary Science and Engineering Laboratory.

We seek creative and innovative individuals who are eager to work in a collaborative and interdisciplinary research environment, have demonstrated excellence in research, and show drive to become leaders in their fields and engage in high-quality teaching and mentoring activity. Candidates conducting research that complements existing strengths in optoelectronics, photonics, renewable energy, or multifunctional composite materials are especially encouraged to apply. The Clare Boothe Luce Assistant Professorship is limited to women who are US Citizens or permanent residents, but otherwise qualified candidates might consider parallel faculty searches in Soft Materials (www.udel.edu/udjobs \#101714) and Nanoscale engineering (www.udel.edu/udjobs \#101735). The University of Delaware combines a rich historic legacy in engineering with a commitment to undergraduate and graduate education and scholarly excellence. With external funding exceeding $\$ 200$ million, the University ranks among the top 100 universities in federal R\&D support for science and engineering. Supported by state-of-the-art facilities, research is conducted across all seven colleges and numerous interdisciplinary institutes and centers. The main campus in Newark, Delaware, provides the amenities of a vibrant college town with convenient access to the major cities of the East Coast. The newly erected 194,000-square-foot Interdisciplinary Science and Engineering Laboratory greatly expands opportunities and resources for interdisciplinary research and education, and the recently acquired 272-acre STAR (Science, Technology and Advanced Research) campus offers even more opportunities for research, academic, and commercial development.

Candidates must have a $\mathrm{PhD}$ degree in engineering or a related discipline. The successful candidate will join the ME or MSE department as appropriate to her area of expertise. Applicants should submit a curriculum vitae, a one-page statement of teaching experience and interests, a 3-6-page research proposal, and a list of at least four references. The University of Delaware values diversity and is supportive of the needs of dual-career couples. Application review will begin by 15 December 2013 and continue until the position is filled.

To submit applications please visit the UDJOBS website at www.udel.edu/udjobs. For additional information about this position contact the Search Committee Chairperson at zide@udel.edu.

Dare to be first.

The UNIVERSITY OF DELAWARE is an Equal T TNIVERSTTYOF Opportunity Employer, and encourages applications 1 EIVERSITYOF 


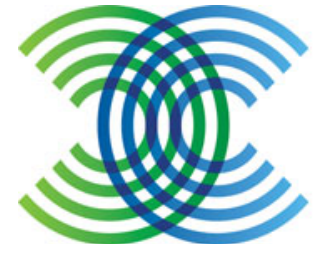

FRONTIER INSTITUTE

OF SCIENCE AND TECHNOLOGY 前沿科学技术研究院

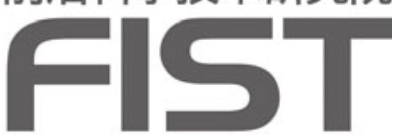

\section{Center Directorships | Tenure-Track Faculty Positions | Postdoctoral Research Fellows}

Frontier Institute of Science and Technology (FIST) Xi'an Jiaotong University (XJTU)
FIST is a large selective investment by XJTU in an effort to establish a world-class, multi-disciplinary research institute. To achieve this goal, FIST is setting up a number of research centers of excellence in Physics, Chemistry, Bio-Science/Life-Science/Basic-Medical-Science, and Materials Science, and adopts a new management system similar to that of most U.S. universities. Ten planned centers have been established recently, and FIST is now recruiting the remaining Center Directors. In addition, FIST invites applications to fill its multiple, full-time tenure-track faculty positions at all levels (from lab director to group leader), as well as postdoctoral positions. See our Chinese ad at http://fist.xjtu.edu.cn/job/show.asp?id=11 for details.

An eligible candidate for the Center Director position should be an internationally renowned scientist and established leader in his/her field, with the ability and will to build his/her center into an internationally recognized center of excellence. Successful candidates will be provided with a sizable start-up package to establish a research center, together with a highly competitive salary. See our Chinese ad at http://fist.xjtu.edu.cn/job/show.asp?id=11 for details.

In addition to the Center Director positions, FIST also invites applications in the above-mentioned areas to fill its tenure-track faculty positions at all levels, from lab director to group leader. Applications for postdoctoral positions are also welcome. An eligible faculty candidate should have a track-record for excellence in research and the potential to lead a lab or a group to success. Successful candidates will be provided with a competitive start-up package including salary lab space, and start-up fund, together with other benefits. Position level and start-up package will vary with the candidate's qualification. See our Chinese ad at http://fist.xjtu.edu.cn/job/ show.asp?id=11 for details.

Interested individuals should set up their free ResearcherID webpage on http://www. researcherid.com/. Please send your ResearcherlD citation information along with a cover letter, $\mathrm{CV}$, and a list of ten representative publications to:

Dr. Xiangli Meng

Frontier Institute of Science and Technology (FIST)

Xi'an Jiaotong University

1 West Building, 99 Yanxiang Road

Yanta District, Xi'an, Shaanxi Province

P.R.China, 710054

Tel/Fax: +862983395131

Email: fist@mail.xjtu.edu.cn

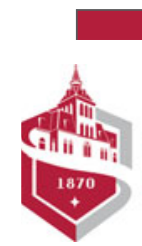

STEVENS INSTITUTE Of TECHNOLOGY

\section{Tenure-Track Assistant Professor}

Chemical Engineering and Materials Science

Stevens Institute of Technology announces a tenure-track faculty opening in the Department of Chemical Engineering and Materials Science (CEMS) starting August 1, 2014. As a leading academic department at Stevens, CEMS has its research centered on problems broadly related to energy, health, and defense that are closely aligned with the ten-year strategic plan of the Institute.

Applicants should have a PhD degree in Chemical Engineering, Materials Science and Engineering, or closely related disciplines. While all relevant areas will be considered, priority will be given to candidates with research interests in sustainable energy or innovative healthcare solutions. Successful applicants will be expected to develop strong extramurally funded research and show a clear commitment to both graduate and undergraduate education in an interdisciplinary environment. The search targets applicants for the rank of assistant professor but applications for higher ranks will also be considered depending on the candidate's experience, record of accomplishments, and national and international recognition.

Applications will be accepted until the position is filled. Applicants should submit a curriculum vitae, a detailed research plan including long-term professional goals, a description of teaching interests, and contact information for at least three references.

Applicants can apply for this position at http://www.apply2jobs.com/Stevens.

Stevens Institute of Technology is an equal opportunity/affirmative action employer and actively seeks the candidacy of women and minorities.

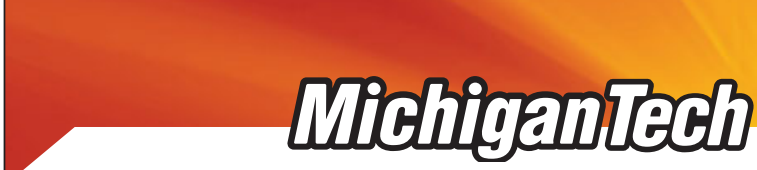 \\ FACULTY POSITION Materials Science and Engineering}

The Materials Science \& Engineering Department at Michigan Technological University invites applications for a tenure-track faculty position at the rank of Assistant, Associate, or Full Professor. Successful applicants will have demonstrated an esteemed record of professional achievement commensurate with rank and the potential to continue and sustain a high-quality, peer-recognized research program. Applicants whose research focuses on traditional structure-property-processing relationships in materials are particularly encouraged to apply. Michigan Tech enrolls approximately 7000 students, of which 4150 are in the College of Engineering. The MSE Department presently enrolls approximately 150 undergraduate and graduate students. Additional information about the search, the MSE Department, Michigan Tech, and the community can be found at www.mtu.edu/materials.

Applications should be submitted electronically to http://www.jobs.mtu.edu/ postings/1188 and will include a copy of the applicant's curriculum vitae, statements of teaching interests and research plans, and a cover letter summarizing qualifications for the position. Contact information for three professional references will be requested at a later time. Applications received by 15 February 2014 will receive full consideration. Nominations or inquiries of a general nature may be directed to msesearch@mtu.edu.

Michigan Tech acknowledges the importance of supporting dual career partners in attracting and retaining a quality workforce (www.dual.mfu.edu). Michigan Tech is an ADVANCE institution, one of a select group of universities in receipt of NSF funds in support of our commitment to increase diversity and the participation and advancement of women in STEM.

Michigan Technological University is an Equal Opportunity Educational Institution/ Equal Opportunity Employer. 


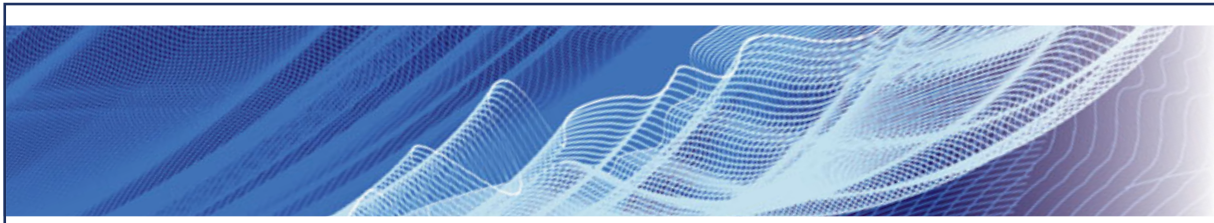

Tenure-Track Assistant Professor

Department of Chemical and Materials Engineering

The Chemical and Materials Engineering (CME) Department at the University of Nevada, Reno (UNR) invites applications for a tenure-track faculty position at the level of Assistant Professor. Preferred specialization areas include both fundamental and applied modeling at (and across) all length scales and application areas focused on Advanced Manufacturing as it relates to Renewable/Sustainable Energy, or Integrated Computational Materials Engineering (ICME). This position is part of a newly forming Advanced Manufacturing cluster that encompasses the departments of Chemical and Materials Engineering, Mechanical Engineering, and Computer Science and Engineering.

Candidates will be expected to develop scholarly excellence through research, instruction, and professional service. This will include teaching of existing courses, development of new undergraduate and graduate course, and should also include development of productive research collaborations both externally and internally within the college, university, and the Advanced Manufacturing collaborative cluster (for more information, see www.unr.edu/cme/). Candidates should hold a doctorate degree in Materials Science and Engineering, Chemical Engineering, or a closely related field.

Reno, on the eastern slope of the Sierra Nevada Mountains, has an area population of 425,000 and is 45 minutes from Lake Tahoe, with excellent recreation, scenic mountains, short commutes, and extensive cultural and entertainment opportunities.
Candidates should submit the following items through the online application system (https://www.unrsearch.com/postings/13795): a cover letter with statement of qualifications, curriculum vitae including a list of publications, a concise summary of past research accomplishments and teaching experience, a statement of future research plans and teaching interests, and contact information for at least three references. The position will be available July 1, 2014. Full consideration will be given to candidates who apply by January 14, 2014.

Contact:

Dr. Jeffrey C. LaCombe, Associate Professor

Chemical and Materials Engineering, MS-388

University of Nevada, Reno

Reno, NV 89557

Tel: 775-784-1797; E-mail: lacomj@unr.edu

EEO/AA Policy: The University of Nevada, Reno, is an Equal Employment Opportunity/Affirmative Action employer and does not discriminate on the basis of race, color, religion, sex, age, creed, national origin, veteran status, physical or mental disability, or sexual orientation in any program of activity it operates. The University of Nevada employs only United States citizens and aliens lawfully authorized to work in the United States.

\section{XJTU-HKUST \\ JoINT SCHOOL OF SUSTAINABLE DEVElopment}

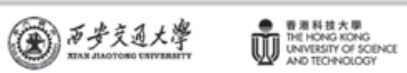

\section{Founding Dean}

With a vision to advance education and research in sustainable development, The Hong Kong University of Science and Technology (HKUST), in partnership with Xi' an Jiaotong University (XJTU), is establishing the XJTU-HKUST Joint School of Sustainable Development (JSSD). Located in Xi'an of PR China and in close collaboration with HKUST's core operation in Hong Kong, the School will focus on educating a new generation of graduates who are capable of contributing to sustainable development, and on undertaking interdisciplinary high-impact research in energy conservation, resource management and environmental protection. English will be the School's language of instruction and other official conduct.

HKUST is a world-class leading research university and has been ranked overall No. 1 university in Asia for the last two years by QS Asian University Rankings ${ }^{\mathbb{B}}$. XJTU, established in 1896 , is in the C9 League, which consists of the top nine prestigious universities in China. The JSSD will have three departments: Sustainable Energy; Sustainable Materials; and Sustainable Systems. Within the next five years, the Schoo is expected to have up to 60 faculty members and an enrollment of more than 1,000 undergraduate and postgraduate students in the three departments.

We are searching for a leading scholar with the vision and capability to be the founding Dean of JSSD. The successful candidate will be a senior academic administrator of HKUST appointed with tenure for posting to the JSSD in Xi'an. The appointee will assume full responsibility for all substantive academic and administrative matters of JSSD, including strategic planning and implementation, organization development, budget planning and control, external publicity, and maintaining relations and linkages with alumni and all relevant parties including governments, institutions and industries. Candidates must meet the high academic and professional standards of the HKUST senior faculty and should possess relevant experience in university administration at the senior level. Proficiency in both English and Chinese is mandatory. Understanding and knowledge of the higher education sector in Hong Kong and the Mainland is essential. Concurrent with a tenured professorial appointment, the appointment as Dean of JSSD will be for an initial term of five years which is renewable. Remuneration is highly competitive with generous benefits.

Applications/nominations together with a curriculum vitae, a vision statement of the development of the School, and the contacts of at least three referees should be sent to the Chairman of the Search Committee for Dean of JSSD, c/o Human Resources Office, The Hong Kong University of Science and Technology, Clear Water Bay, Hong Kong [email jssddsrch@ust.hk]. Review of applications/nominations will begin in December 2013 and will continue until the position is filled. For further information about HKUST, XJTU and JSSD, please visit the following websites: HKUST - http://www.ust.hk; XJTU http://www.xjtu.edu.cn/en/index.html; JSSD - http://www.jssd.ust.hk/en/home.htm (Information provided by applicants will be usedfor recruitment and otheremployment-related purposes.)
PROFESSOR AND GIBSON CHAIR IN ENGINEERING College of Engineering | University of Tennessee, Knoxville

The College of Engineering at the University of Tennessee, Knoxville (UTK) is seeking a qualified individual for the position of Professor and Gibson Chair in Engineering. The Gibson Chair in Engineering will focus on expanding energy-related research in the college and will hold an appointment in one or more of the following engineering departments: Chemical Engineering, Civil and Environmental Engineering, Electrical Engineering and Computer Science, Materials Science and Engineering, or Mechanical Engineering. Applicants must hold a doctorate degree in an engineering discipline or a related field and must be eligible for appointment at the rank of full professor.

Please visit http://www.engr.utk.edu/employment/gibson search 2013 $\mathrm{html}$ to view the complete position announcement and application instructions. Review of applications began in November 2013 and will continue until the position is filled. Anticipated start date is on or after August 1, 2014

The University of Tennessee is an EEO/AA/Title VI/Title IX/Section 504/ADA/ ADEA institution in the provision of its education and employment programs and services. All qualified applicants will receive equal consideration for employment without regard to race, color, national origin, religion, sex, pregnancy, marital status, sexual orientation, gender identity, age, physical or mental disability, or covered veteran status.

THE UNIVERSITY of TENNESSEE 비 KNOXVILLE COLLEGE of ENGINEERING 


\section{Southern Connecticut State University}

\section{TENURE-TRACK FACULTY POSITION Department: PHYSICS}

Rank: Assistant/Associate Professor

Specialization(s): Bio-physics or bio-nanotechnology, high-resolution imaging of biomaterials; experimentalist preferred.

Brief Description of Duties/Responsibilities: Teaching of introductory, upper and master's degree-level courses for physics and other science majors, and elementary core courses for other undergraduates; mentoring majors; scholarly research with strong potential for undergraduate and master's degree student participation including establishing a laboratory in a new science building now under construction (anticipated opening, spring 2015); scientific interaction with departmental faculty; participation in collegial service and professional activities. Successful candidate will be expected to help develop the recently established master's program in applied physics.

Candidate must be committed to teaching within a vibrant/demanding public liberal arts and sciences environment, and demonstrate the potential for excellence in teaching, mentoring and research with undergraduates. All faculty at SCSU share in academic advising and participate in department/university service. Nominal teaching load is 12 credit-hours per semester.

Tenure-track faculty at SCSU are expected to conduct creative activity/research in their area of expertise. These activities include, but are not limited to, research leading to publication of books and/or articles in academic and professional journals, performances in the fine and performing arts, seeking funding in support of research and teaching needs, and contributing to workshops and conferences.

SCSU is a student-centered institution and we regard student success as our highest priority. We seek to instill in all of our students the value of the liberal arts and sciences as a foundation for professional development and life-long learning.

Required Qualifications: Ph.D. in physics, bio-physics, material science or closely related field and a demonstrated commitment to undergraduate education with evidence of teaching effectiveness and ability to perform research that potentially involves undergraduate and master's degree students, preferably in collaboration with current department faculty.

Preferred Qualifications: Primary interest in bio-materials physics or bio-nanotechnology, experimentalist preferred in the field of high resolution imaging of biomaterials using novel imaging technologies. Preference will be given to applicant committed to collaborating with one or more of the current faculty members. In addition to excellence in teaching, we value participation in the scientific community by faculty and students. Our department houses a significant component of an NSF-supported Materials Research Science and Engineering Center, in collaboration with Yale University (http://www.crisp.yale.edu/) and a Nanotechnology Center.

Application Process: Please submit letter of interest, curriculum vitae, letter describing professional goals and statement of teaching perspective and scholarly interests. Identify at least three references with e-mail addresses and phone numbers. Send materials to: Dr. Christine Broadbridge, Chairperson, Department of Physics, Southern Connecticut State University, 501 Crescent St., New Haven, CT 06515 or e-mail to: physics@southernct.edu. In order for your application to be given full consideration, all materials must be received by January 15, 2014. Position will remain open until filled.

\section{$E O E$}

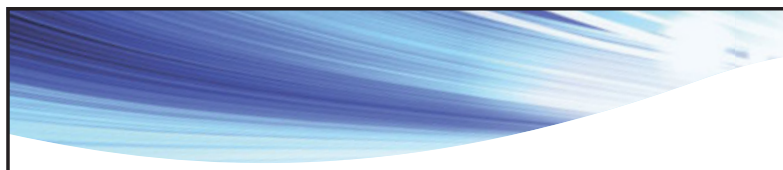

DEAN | College of Polymer Science and Polymer Engineering

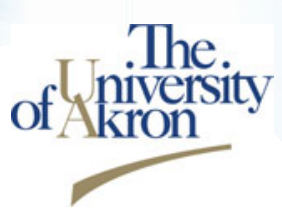

The University of Akron invites nominations and applications for the position of Dean of the College of Polymer Science and Polymer Engineering (CPSPE) at The University of Akron. CPSPE is an internationally renowned college focused on graduate research education with 40 research active faculty members and 320 graduate students. The successful candidate will hold a PhD degree in Chemistry, Physics, Polymer Engineering or Science, Chemical Engineering, Materials Science and Engineering, or a closely related field; have a distinguished research record; and have administrative experience. For additional information on CPSPE, visit http://www.uakron.edu/cpspe/.

For complete information and to apply for this position, please visit: http://www.uakron.edu/jobs. Job ID\# 8150. EEO/AA

\section{0

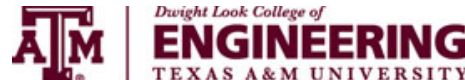

\section{NON-TENURE TRACK FACULTY POSITIONS}

\section{Dwight Look College of Engineering \\ Texas A\&M University}

The Dwight Look College of Engineering at Texas A\&M University invites applications for non-tenure track faculty positions. Specifically targeted are candidates with experience and interests in materials corrosion in extreme service conditions. Applicants for the non-tenure track titles of associate professor or professor of engineering practice must have a $\mathrm{PhD}$, Master, or Bachelor level degree in materials science and engineering, physics, chemistry, or in a related field, and significant industry and/or government lab experience. Candidates for associate professor or professor of engineering practice may be considered for multiyear appointments. The successful applicants will be expected to teach at the undergraduate and graduate level, develop curriculum and implement new teaching methods related to distance education and outreach programs, participate in the department's mission, and serve the profession. It is also expected that the candidate will supervise undergraduate/graduate research and collaborate with other faculty on externally funded research projects in the field. Strong written and verbal communication skills are required. Applicants will be evaluated based on current credentials and potential for impact in delivering real-world scenarios related to engineering education.

The Texas A\&M Engineering Experiment Station (TEES), a state agency of Texas, also seeks research faculty in the non-tenure track titles of associate research professor or research professor with research experience and interests in materials corrosion in extreme service conditions. Candidates for these titles must have a $\mathrm{PhD}$ degree in materials science and engineering, physics, chemistry, or in a related field, and research experience and accomplishments relative to the rank being sought. Successful candidates will be expected to develop and maintain a funded quality research program in materials corrosion, and contribute to improving the economic development and quality of life in Texas and the nation.

Applicants must apply and include a cover letter clearly stating the position being sought, curriculum vitae, teaching statement, and a list of four references (including their postal addresses, telephone numbers and e-mail addresses) to the web site: www.tamuengineeringjobs.com/applicants/ Central?quickFind $=54963$

The full position ad can be found at msen.tamu edu. Full consideration will be given to applications received by February 15, 2014. Applications received after that date may be considered until positions are filled. It is anticipated that the appointment will begin in fall 2014

Texas A\&M University is an Equal Opportunity Employer 